\title{
Potential contribution of natural enemies to patterns of local adaptation in plants
}

\author{
Lisèle Crémieux ${ }^{1}$, Armin Bischoff ${ }^{1}$, Majka Šmilauerová2, Clare S. Lawson ${ }^{3}$, Simon R. Mortimer ${ }^{3}$, Jiř́ Doležal ${ }^{2}$, \\ Vojtěch Lanta ${ }^{4}$, Andrew R. Edwards ${ }^{3}$, Alex J. Brook ${ }^{3}$, Thomas Tscheulin ${ }^{5}$, Mirka Macel ${ }^{6}$, Jan Lepš², \\ Heinz Müller-Schärer ${ }^{1}$ and Thomas Steinger ${ }^{1}$ \\ ${ }^{1}$ University of Fribourg, Department of Biology, Unit of Ecology and Evolution, Chemin du musée 10, CH-1700 Fribourg, Switzerland; ${ }^{2}$ University of South \\ Bohemia, Faculty of Science, Department of Botany, Branišovská 31 CZ-37005 České Budějovice, Czech Republic; ${ }^{3}$ University of Reading, Centre for \\ Agri-Environmental Research, Earley Gate, PO Box 237, Reading RG6 6AR, UK; ${ }^{4}$ Institute of Botany CAS CZ, Dukelská 135, 379 01 Třeboň, Czech Republic; \\ ${ }^{5}$ Laboratory of Biogeography and Ecology, University of the Aegean, Department of Geography, University Hill, GR-81100 Mytilene, Greece; ${ }^{6}$ Netherlands \\ Institute of Ecology (NIOO-KNAW), PO Box 40, 6666 ZG Heteren, the Netherlands
}

\begin{abstract}
Summary
- Genetic differentiation among plant populations and adaptation to local environmental conditions are well documented. However, few studies have examined the potential contribution of plant antagonists, such as insect herbivores and pathogens, to the pattern of local adaptation.

- Here, a reciprocal transplant experiment was set up at three sites across Europe using two common plant species, Holcus lanatus and Plantago lanceolata. The amount of damage by the main above-ground plant antagonists was measured: a rust fungus infecting Holcus and a specialist beetle feeding on Plantago, both in low-density monoculture plots and in competition with interspecific neighbours.

- Strong genetic differentiation among provenances in the amount of damage by antagonists in both species was found. Local provenances of Holcus had significantly higher amounts of rust infection than foreign provenances, whereas local provenances of Plantago were significantly less damaged by the specialist beetle than the foreign provenances. The presence of surrounding vegetation affected the amount of damage but had little influence on the ranking of plant provenances.

- The opposite pattern of population differentiation in resistance to local antagonists in the two species suggests that it will be difficult to predict the consequences of plant translocations for interactions with organisms of higher trophic levels.
\end{abstract}

Key words: competition, Holcus lanatus, local adaptation, plant-antagonist interaction, Plantago lanceolata, population differentiation, reciprocal transplant.

\section{Introduction}

The invasion of exotic plant species into natural communities has been shown to alter interactions between community members, with sometimes dramatic impact on the composition, diversity and behaviour of organisms of higher trophic levels (Levine et al., 2003; Lau, 2006). Apart from exotic species, foreign genotypes may also be introduced within the distributional range of a species, such as in the context of biodiversity restoration efforts (Hufford \& Mazer, 2003). An example where the accidental introduction of a superior genotype has had substantial ecological consequences is the cryptic invasion of Phragmites australis in North America, which has led to considerable expansion of the species' range (Saltonstall, 2002) and displacement of the native genotypes and other plant species.

Evolutionary theory suggests, however, that superior performance of foreign genotypes within a given species should be rare in nature, as native genotypes are expected to be better 
adapted to the environmental conditions at their native site (Linhart \& Grant, 1996; Kawecki \& Ebert, 2004). Indeed, local adaptation seems to be common in plants, as evidenced by the large number of reciprocal transplant studies demonstrating superior performance of local over foreign transplants at a given study site (Galloway \& Fenster, 2000; Montalvo \& Ellstrand, 2000; Joshi et al., 2001). Most studies on local adaptation in plants have focused on abiotic factors, such as soil characteristics and climatic conditions as the dominant selective force promoting adaptive population differentiation (Joshi et al., 2001; Bischoff et al., 2006; Macel et al., 2007). By contrast, relatively little is known about the potential contribution of biotic factors, such as herbivores and pathogens, to local plant adaptation. Herbivores and pathogens can have strong impacts on plant fitness (Marquis, 1992; Jarosz \& Davelos, 1995), and interactions with plants often vary greatly in time and space (Thompson, 1999; Lau, 2006; Nuismer, 2006), providing opportunity for genetic differentiation between populations and adaptation to local antagonist assemblages. Such local adaptation would be evidenced in a reciprocal transplant experiment by higher degrees of resistance (i.e. lower amounts of damage) of native genotypes compared with foreign genotypes. However, few reciprocal transplant studies have measured amount of damage by herbivores or pathogens to examine their contribution to local adaptation in plants (Sork et al., 1993; Dechamps et al., 2008). The evolutionary consequences of differential selection by antagonists has frequently been studied in the context of exotic plant invasions, where a plant species is introduced into an area outside its distributional range and thereby escapes from its natural enemies (Keane \& Crawley, 2002). Such enemy release is expected to lead to an evolutionary decline in biotic resistance (EICA hypothesis, Blossey \& Nötzold, 1995). By contrast, our study examines local adaptation in resistance to potentially the same enemy species.

Plant resistance to antagonists is a complex trait mediated by a large number of genes and modified by environmental conditions prevailing in the field (Rossi \& Stiling, 1998; Stiling \& Bowdish, 2000; Kittelson, 2004). In addition to genetic differentiation in resistance driven by local antagonists, the environmental dependency of the phenotypic expression of resistance opens up a second mechanism by which native genotypes may experience less damage by antagonists than foreign genotypes. The plant stress hypothesis postulates that abiotic stress decreases plant resistance to herbivores (White, 1984). Following this line of reasoning, one might expect local plant genotypes to succumb less to abiotic stress than foreign ones and therefore have higher anti-parasite resistance and/or tolerance at their native site. In this scenario, higher resistance of native genotypes would represent an evolved response to divergent selection by abiotic factors rather than by parasites. Lower rates of damage by antagonists on local versus foreign genotypes could thus act to reinforce the pattern of local adaptation in fitness.
To examine the interaction of plant populations of different provenances with their antagonists, and thus the potential contribution of natural enemies to local adaptation in plants, we measured herbivory and pathogen infection in a reciprocal transplant experiment using two common plant species, Holcus lanatus and Plantago lanceolata. We previously reported superiority in fitness components of local over foreign provenances of both species (Bischoff et al., 2006). Since plant neighbours can influence attack rates and degrees of resistance in plants (Agrawal et al., 2006; Barton \& Bowers, 2006), the effect of surrounding vegetation on plant-antagonist interactions was investigated by growing plants both in monocultures and in competition with the characteristic local plant community. Furthermore, to obtain information on the scale at which population differentiation in resistance occurs, we measured differences in damage by antagonists on populations sampled at two different spatial scales: at a continental scale by reciprocally exchanging seeds among three European countries encompassing a large climatic gradient; and at a regional scale by including at each site an additional population originating from a contrasting habitat in the vicinity $(<100 \mathrm{~km})$ of the study sites. The inclusion of the second 'local' population was aimed at minimizing geographic distance from the study site while maximizing environmental distance.

We asked the following specific questions:

- Are the various provenances of the two study species damaged differently by herbivores and pathogens?

- Are local plants less damaged by antagonists than foreign plants, indicating local adaptation expressed in resistance? - Are these patterns of resistance different in low-density monoculture plots as compared with high-density mixture plots? - How large is population differentiation in resistance between contrasting habitats at a small spatial scale (within countries) compared to that at a large scale (between countries).

\section{Materials and Methods}

\section{Plant species}

The two plant species used in this experiment, the grass Holcus lanatus L. (hereafter Holcus) and the herb Plantago lanceolata L. (hereafter Plantago), are both widely distributed in the northern hemisphere, and occur in a wide range of grassland habitats (Cavers et al., 1980; Thompson \& Turkington, 1988). Both species are short-lived perennials that can regenerate vegetatively, but spread mainly by seeds. Plantago is windpollinated with a gametophytic self-incompatibility system (Ross, 1973). Gene-flow distances are on the order of 0.8$1.5 \mathrm{~m}$ for pollen-mediated gene flow, and only $0.04-0.35 \mathrm{~m}$ for seed-mediated gene flow (Tonsor, 1985; Bos et al., 1986). Holcus is also wind-pollinated and predominantly outcrossing (Beddows, 1961). Gene-flow distances are not known, but the large surface of the spikelets facilitates dispersal of the seeds by wind (Beddows, 1961). 


\section{Study sites and seed provenances}

The reciprocal transplant experiment (see also Bischoff et al., 2006) was conducted at three sites within Europe: Czech Republic (CZ), United Kingdom (UK) and Switzerland (CH), representing distinct macroclimatic conditions. The climate at the UK site is typically Atlantic (temperatures, January : July, $4.3: 17.2^{\circ} \mathrm{C}$; rainfall, $\left.651 \mathrm{~mm} \mathrm{yr}^{-1}\right)$, at the Czech site subcontinental (temperatures, January : July, $-1.8: 17.7^{\circ} \mathrm{C}$; rainfall, $588 \mathrm{~mm} \mathrm{yr}^{-1}$ ), and temperatures at the Swiss site (January : July: $-1.0: 17.6^{\circ} \mathrm{C}$ ) are similar to those at the Czech site but precipitation $\left(1119 \mathrm{~mm} \mathrm{yr}^{-1}\right)$ is much higher than at both other sites. Pairwise geographic distances between the experimental sites were $600 \mathrm{~km}(\mathrm{CH}-\mathrm{CZ}), 800 \mathrm{~km}$ (CH-UK) and $1100 \mathrm{~km}$ (CZ-UK). In each country, seeds of the two species were collected from large grassland populations where the species had not been sown in recent decades. At least 70 Plantago and 80 Holcus mother plants per population, randomly chosen and separated by at least $5 \mathrm{~m}$, were sampled and their seeds bulked. These populations were in close proximity to the study site $(\mathrm{CH}, \mathrm{UK},<1 \mathrm{~km}$; CZ, $3 \mathrm{~km}$ for Plantago, $16 \mathrm{~km}$ for Holcus) and experienced similar environmental conditions (subsequently referred to as the 'home' population): in the UK, a chalk grassland, and in the Czech Republic and Switzerland mesotrophic grasslands, all three with plant communities characterized by Arrhenaterum elatius (Poaceae; see Bischoff et al. (2006) for further details). These seeds were reciprocally exchanged among the three countries. In addition, we also collected seeds within each country from a population relatively close to the study site $(\mathrm{CH}, 7 \mathrm{~km}$; $\mathrm{UK}$, $27 \mathrm{~km}$; CZ, $28 \mathrm{~km}$ for Holcus, $100 \mathrm{~km}$ for Plantago) but experiencing contrasting environmental conditions (subsequently referred to as the 'local different' population). The contrasting habitat was drier than the home habitat in Switzerland (oligotrophic grassland) and the Czech Plantago population (chalk grassland), but wetter in the UK (mesotrophic, moist grassland). For the Czech Holcus plants, the main within-country difference was altitude and its related climate (montaneous, medium-moist grassland). Distances between habitats within countries were $7 \mathrm{~km}(\mathrm{CH}), 28 \mathrm{~km}(\mathrm{UK})$, and 44-100 km (CZ, Holcus and Plantago, respectively). The seeds from the 'local different' populations were not reciprocally exchanged between countries, but only grown at the study site within the country of origin. The aim here was to compare population divergence in parasite resistance at small spatial scales but contrasting habitat (within country) with that at larger scales but similar habitat (between countries).

\section{Experimental design}

At each of the three study sites, and for each of the two species, 64 plots arranged in eight replicate blocks were established in an agricultural field that was previously ploughed to remove the existing vegetation. Seeds of a single species and provenance were sown in November 2002 in the central grid of the $2 \times 2$ m plots ( 20 cells of $0.2 \times 0.2 \mathrm{~m}$ ), with 10 seeds per grid cell. To establish the competition treatment, mixtures of 10 characteristic grassland species from each site were additionally sown in half of the plots at a density of 3000 seeds $\mathrm{m}^{-2}$ (seeds from local suppliers, see Bischoff et al., 2006 for species composition of the mixtures at each site). Thus, at each site there were a total of eight treatment combinations per species (four provenances $\times$ two competition treatments), randomly arranged within each of eight replicate blocks per species. After recording seedling emergence in spring 2003, the number of seedlings was reduced to one plant per grid cell, that is, generally 20 seedlings per plot, and five focal plants per plot were randomly selected and labelled for further measurements, resulting in a potential sample size of 320 plants per species (40 plants per treatment) and site. Owing to low seedling emergence and few plant losses, the realized sample size was between 72 and 315 (median 220) plants per species and site.

\section{Measurements of pathogen infestation and herbivory}

All measurements reported in this study were made in the second year of the experiment, thus on established plant communities. In Holcus, the main above-ground plant antagonist was a rust fungus (Puccinia sp., most likely P. coronata or $P$. recondita). These rust species can parasitize a number of grass species, and are considered to represent a complex of rusts. Each member of the complex is given a subspecies name depending on the particular host grass species on which it occurs (Gardner $\&$ Hodges, 1989). We scored all tillers of five focal plants per plot for presence/absence of rust pustules. The degree of infection was estimated on one representative leaf of six infected tillers per plant using standard area diagrams developed for cereal rusts $(0$, no infection; $1,1 \% ; 2,20 \% ; 3,50 \%$; 4, $100 \%$ relative disease severity; Zadoks \& Schein, 1979). Infection rates were calculated for each of the five focal plants per plot as (\% infected tillers) $\times$ (average score of the six tillers). The surveys were done when rust infection was at a maximum: 28-29 September in Switzerland, 29 September to 1 October in the UK, and 20-22 September in the Czech Republic.

In Plantago, the main above-ground plant antagonists were leaf-chewing herbivores. Punch holes caused by Longitarsus leaf beetles (Coleoptera: Chrysomelidae) were the only visible type of damage at the UK site and the dominant damage type at the Czech and Swiss sites. The most abundant species observed was Longitarsus pratensis, which feeds on several Plantago species, including P. lanceolata (Douget, 1994). We measured chrysomelid damage (punch holes) as follows: first, all leaves of the five focal plants per plot were scored for the presence/absence of herbivory; then for each plant a subset of six fully expanded leaves showing herbivore damage was selected (evenly distributed over the plant and representative of the size and age range 
present) and the extent of herbivore damage was estimated by comparing damage on leaves with a template with 10 damage levels $(1,0-1 \%$; $2,1-2 \%$; 3, 2-3\%; 4, 3-4\%; 5, 4-5\%; 6, 5$10 \%$; 7, 10-15\%; 8, 15-20\%; 9, 20-30\%; $10,>30 \%$; adapted from Carson \& Root, 2000). Damage was calculated for each measured plant as ( $\%$ leaves with damage) $\times$ (average score of the six leaves). The census dates were chosen to match peak activity of the chrysomelid larvae: 5-6 July in the UK, 28 June to 1 July in Switzerland and 29 June to 7 July in the Czech Republic. At the end of the growing season, foliage invertebrates were collected at the UK (28 September) and $\mathrm{CH}$ (8 October) sites using a vortis suction sampler to examine beetle number and diversity. A single suck lasting $10 \mathrm{~s}$ was made on each focal plant, and the content of the focal plants pooled for each plot. The samples were stored in $70 \%$ ethanol and invertebrates (chrysomelids and weevils) were later identified in the UK. The number of individuals of each species was recorded, and the total number of phytophagous beetles as well as the total number of beetles known to feed on Plantago (Bullok, 1992) were calculated for each plot. Values were corrected for the number of plants sampled per plot (no. of beetles per plant). To account for differences in plant size between treatments, and thus enable the comparison between beetle abundance and amount of damage, we also calculated the number of beetles per metre of leaf as follows: no. of beetles per plant/average cumulative leaf length at the time of sampling.

\section{Data analysis}

We used mixed-effect models as implemented in SAS V9 (PROC MIXED) to examine the influence of study site, plant provenance and competition treatment on amount of parasitism separately for each species. All models contained fixed main and interaction effects as a result of site, provenance and competition, and random effects owing to block nested within site. All analyses were done on plot means.

Separate models were run to test for local adaptation and to examine the scale of population divergence. The former model included the three provenances that were reciprocally exchanged between countries, whereas the latter model included, in addition, the 'local different' provenance that was unique for each country.

To test for local adaptation in anti-parasite resistance, we used the 'home vs foreign' criterion (Kawecki \& Ebert, 2004). Local adaptation is indicated if the local provenance is more resistant to antagonists than the foreign provenances at its native site. We specified the 'home vs foreign' linear contrasts within significant site-by-provenance interactions. We calculated an overall contrast, simultaneously comparing the home vs foreign contrasts at all three sites $(\mathrm{df}=3)$. If this overall contrast was significant, we tested the home vs foreign contrast separately for each site (three contrasts with $\mathrm{df}=1$ ). As a check, we also specified contrasts which compare the diagonal (the three 'home' combinations) with the off-diagonal (three sites $\times$ two 'foreign' provenances) in the site $X$ provenance matrix, but this analysis gave very similar results, so we only report the former contrasts.

To examine the scale of population differentiation, the effect of plant provenance was tested with four levels: 'home', 'within country', foreign 1 (the closest of the two foreign origins) and foreign 2 (the furthest of the two foreign origins). The actual seed provenance behind each level was therefore different at each site. Linear contrasts of 'home' vs 'local different' and 'home' vs 'foreign' were specified within the provenance effect or the appropriate interaction. Variables were transformed where necessary (as indicated in Table 1) to meet the assumptions of the analysis.

Table $1 F$-values and significance of site, provenance and competition effects on parasitism

\begin{tabular}{|c|c|c|c|c|}
\hline & \multirow{2}{*}{$\frac{\text { Holcus }}{\text { Rust infection }}$} & \multicolumn{3}{|l|}{ Plantago } \\
\hline & & Beetle damage & No. of beetles per plant & No. of beetles $\mathrm{m}^{-1}$ leaf \\
\hline Site $\left(d f=2^{a}\right)$ & $28.30 * * *$ & $28.42 * * *$ & 1.06 & $30.56^{* * *}$ \\
\hline Provenance $\left(\mathrm{df}=2^{\mathrm{a}}\right)$ & $26.83 * * *$ & 1.19 & $13.43 * *$ & $5.64^{*}$ \\
\hline Site $\times$ provenance $\left(\mathrm{df}=4^{\mathrm{a}}\right)$ & $9.75 * * *$ & $4.94^{* *}$ & 0.17 & 0.83 \\
\hline Home vs foreign ${ }^{b}(d f=3)$ & $9.00 * * *$ & $4.50^{* *}$ & - & - \\
\hline Competition $(\mathrm{df}=1)$ & $13.87^{* *}$ & $18.89 * * *$ & $22.92 * * *$ & 0.51 \\
\hline Site $\times$ competition & 0.49 & $3.18^{*}$ & 2.99 & 0.49 \\
\hline Provenance $\times$ competition & 0.57 & 0.88 & 2.29 & 1.88 \\
\hline Site $\times$ provenance $\times$ competition & 2.06 & 0.72 & 0.57 & 0.004 \\
\hline
\end{tabular}

Beetle damage was log-transformed; no. of beetles per plant and no. of beetles $\mathrm{m}^{-1}$ leaf were square-root transformed before analysis. Block effects were included in the model (not shown).

${ }^{\mathrm{a}} \mathrm{df}=1$ for no. of beetles per plant.

bLinear contrast, specified within significant site $\times$ provenance interaction (three-way interaction with competition not significant) to test for local adaptation.

${ }^{*} P<0.05 ;{ }^{*} P<0.01 ;{ }^{*}{ }^{*} P<0.001$. 


\section{Results}

\section{Holcus infection by a rust pathogen}

Overall, the amount of rust infection in Holcus was high at all three sites, with $92-100 \%$ of the plants showing symptoms of infection. There was significant variation among sites in the percentage of tillers infected $(\mathrm{CH}, 85 \%$; $\mathrm{CZ}, 85 \%$; UK, $60 \%)$ and in the percentage of leaf area covered by the rust on infected leaf blades $(\mathrm{CH}, 50 \%$; CZ, $50 \%$; UK, $20 \%)$, with the UK site showing lower amounts of infection than the $\mathrm{CH}$ and $\mathrm{CZ}$ sites (Table 1, Fig. 1).
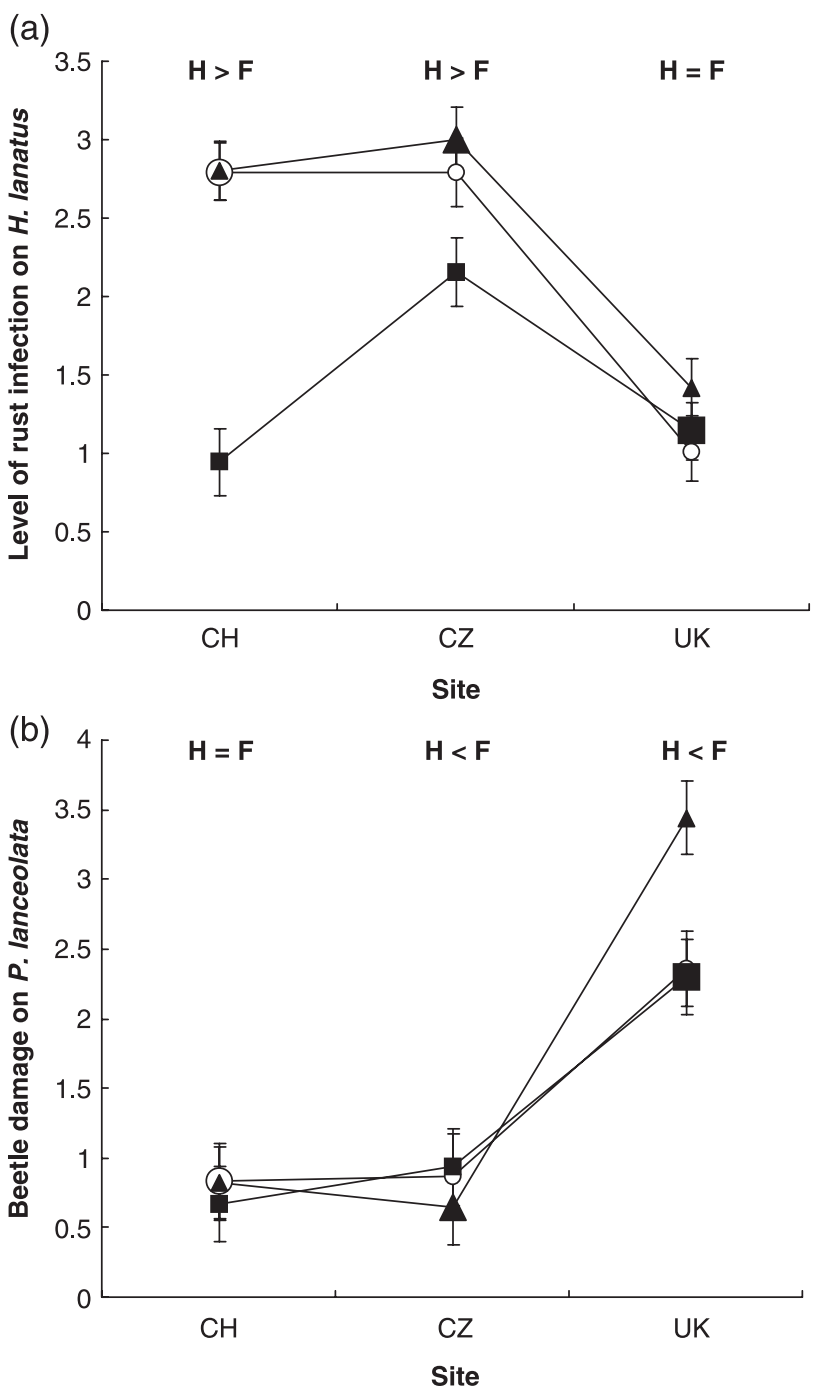

Fig. 1 Rust infection on Holcus (a) and chrysomelid beetle damage on Plantago (b) of the three seed provenances (circles, $\mathrm{CH}$ (Switzerland); triangles, CZ (Czech Republic); squares, UK) in a reciprocal transplant experiment. Damage calculated as (\% tillers or leaves with damage) $\times$ (average score of six leaves). Larger symbols indicate populations growing at their home site. $\mathrm{H}$, home; $\mathrm{F}$, foreign. Significant home vs foreign contrasts are indicated as $\mathrm{H}<\mathrm{F}$ or $\mathrm{H}>\mathrm{F}$. LSMeans \pm SE.
Plants growing under reduced competition in monoculture plots had significantly higher amounts of infection $(+20 \%$, data not shown) than plants growing under competition with a mixed plant community (Table 1). However, there were no significant interactions between competition and seed provenance, and therefore we present results averaged over competition treatments in the following analysis of local adaptation (provenance $\times$ site interaction).

There was a highly significant main effect of provenance and a significant provenance $\times$ site interaction on amounts of infection. Partitioning the provenance $\times$ site interaction into home vs foreign contrasts revealed significant effects. Local provenances of Holcus had a higher amount of infection than foreign provenances (overall contrast $F_{3,89}=9.00, P<0.0001$; Table 1 and Fig. 1). In separate analyses for each site, the 'home vs foreign' contrast was significant at the $\mathrm{CH}$ and $\mathrm{CZ}$ site. These results indicate maladaptation of Holcus to its local pathogen strain. However, a closer inspection of data reveals that the significant home vs foreign contrast is mainly the result of the much lower amount of infection of the UK genotype at the two foreign sites rather than strong changes in the rank of genotypes across the sites (Fig. 1).

In the model including the 'local different' provenances (seeds collected from a different habitat close to the home site within each country), seed origin had a significant main effect on the amount of rust infection $\left(F_{3,126}=15.52, P<0.0001\right)$. Contrasts specified within the significant site $\times$ provenance interaction $\left(F_{6,126}=14.48, P<0.0001\right)$ revealed significant differences between the 'home' and the 'local different' provenances $\left(F_{3,125}=14.30, P<0.0001\right)$. However, when separately analysing each site, we found a significant contrast only for the $\mathrm{CH}$ site, with the home provenance showing higher amounts of infection than the 'local different' provenance (Fig. 2). These data indicate that in Switzerland the degree of population differentiation in disease resistance was similar at the small scale between different habitats and at the large scale between countries.

\section{Plantago damage by chrysomelid beetles}

Chrysomelid beetles were the only above-ground plant antagonists of Plantago at the UK site, and the main agents of leaf damage at the $\mathrm{CH}$ and $\mathrm{CZ}$ sites. Indeed, $>50 \%$ of the leaves of all plants at the three sites showed punch hole damage. The sites differed significantly in damage scores (Table 1), with the UK site showing greater damage than the $\mathrm{CH}$ and $\mathrm{CZ}$ site (UK, $4.5 \%$; $\mathrm{CH}, 1.5 \%$; $\mathrm{CZ}, 1.5 \%)$. In the suction samples collected at the $\mathrm{UK}$ and $\mathrm{CH}$ sites at the end of the season, $88 \%$ of all phytophagous insects known to feed on Plantago were Longitarsus pratensis (Chrysomelidae; specialists of the genus Plantago). The two sites did not differ significantly in number of beetles per plant, but the UK site had a higher number of beetles per metre of leaf than the $\mathrm{CH}$ site (Table 1).

Plants growing in mixed communities had significantly greater damage compared with plants in monocultures $(+33 \%)$, 
(a)

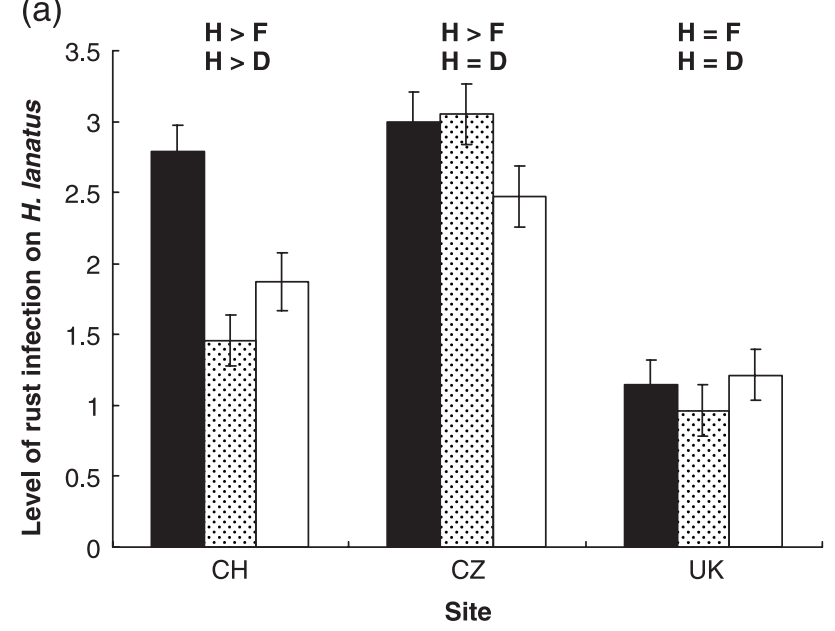

(b)

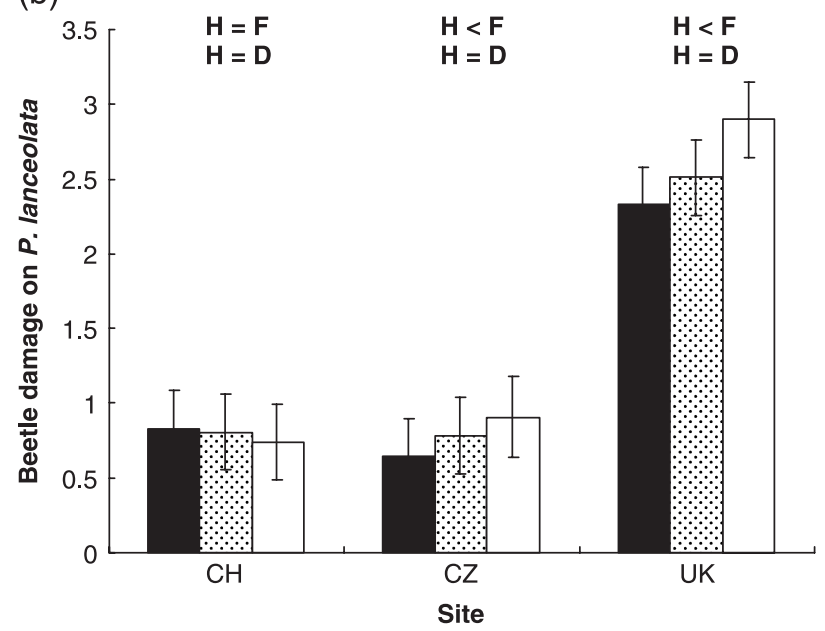

Fig. 2 Rust infection on Holcus (a) and chrysomelid beetle damage on Plantago (b) of the four seed provenances (two foreign provenances pooled) at the three experimental sites. Damage calculated as ( $\%$ tillers or leaves with damage) $\times$ (average score of six leaves). $\mathrm{H}$, home (black bars); $\mathrm{F}$, foreign (white bars); $\mathrm{D}$, 'local different' (grey bars). Significant contrasts indicated as $\mathrm{H}>\mathrm{F}, \mathrm{H}<\mathrm{F}$ or $H>$ D. LSMeans \pm SE.

although fewer individuals of Plantago-feeding beetles were recovered in the mixtures at the end of the growing season $(-40 \%)$. After correcting for differences in plant size (no. of beetles $\mathrm{m}^{-1}$ leaf), there was no difference in beetle abundance between the two competition treatments (Table 1). Interaction effects between competition and seed provenance were not significant for the three measurements given in Table 1, and therefore we describe results for competition treatments averaged in the following analysis of local adaptation.

There was no significant main effect of provenance on beetle damage, but a significant provenance $\times$ site interaction (Table 1). The overall 'home vs foreign' contrast was significant $\left(F_{3,99}=4.50, P=0.005\right)$. Separate analyses for each site showed that at the $\mathrm{CZ}$ and $\mathrm{UK}$ sites the respective home provenances were significantly less damaged than the foreign provenances (Fig. 1). Plant provenance affected the number of Plantago-feeding beetles recovered in the suction samples, both for beetles per plant and for beetles $\mathrm{m}^{-1}$ leaf, with fewer beetle individuals recovered from UK plants than from $\mathrm{CH}$ plants (Fig. 3). The provenance $\times$ site interaction was not significant for the number of beetles. However, the number of beetle $\mathrm{m}^{-1}$ leaf is generally in agreement with the observed amount of damage per plant (home $<$ foreign at the UK site, home $=$ foreign at the $\mathrm{CH}$ site; Fig. 3).

The model including the 'local different' seed origin revealed no significant main effects of provenance on amount of damage $\left(F_{3,141}=1.57, P=0.199\right)$ and on beetle abundance (beetles per plant, $F_{2,67}=1.08, P=0.344$; beetles $\mathrm{m}^{-1}$ leaf, $F_{2,66}=0.67$, $P=0.515)$, but significant interaction effects of provenance with site (damage, $F_{6,141}=2.58, P=0.021$; beetles per plant, $F_{2,67}=8.78, P=0.0004$; beetles $\mathrm{m}^{-1}$ leaf, $F_{2,66}=4.38$, $P=0.016)$. However, 'home vs local different' contrasts were nonsignificant at all sites (Figs 2, 3), indicating low population differentiation in herbivore resistance at small geographical scales.

\section{Discussion}

\section{Differences between provenances depend on site}

Our results show that plants of different provenance are colonized differently by herbivores and pathogens across sites. In Holcus, amounts of rust infection varied up to twofold across sites and 1.5- to threefold among provenances at a given site. In Plantago, beetle abundance was 1.4-fold higher on the $\mathrm{CH}$ plant origin at both studied sites. Interestingly, the phenotypic expression of among-provenance variation in hostplant resistance, as measured by amount of damage, was highly dependent on the study site in both species. For example, at the $\mathrm{CH}$ site, severity of infection by the rust fungus was $67 \%$ lower in the most resistant provenance of Holcus than in the least resistant provenance, whereas at the UK site the difference was $29 \%$. Similarly, amount of damage in Plantago was $48 \%$ higher on the least resistant provenance compared with the most resistant one at the UK site, while this difference was only $25 \%$ at the $\mathrm{CH}$ site.

This site-dependent variation among provenances in resistance may reflect differences among provenances in genetically based resistance against local assemblages of antagonist genotypes ( $\mathrm{G} \times \mathrm{G}$ interactions); and/or different responses of provenances to local abiotic site conditions ( $\mathrm{G} \times \mathrm{E}$ interactions), which may indirectly affect resistance and/or tolerance. Our experimental setup does not allow differentiation between these two possibilities because site conditions and antagonist assemblages are confounded. In addition to genetic factors, environmentally induced maternal effects may have contributed to amongprovenance differences in resistance. Maternal effects are known mainly to affect early plant growth, but were also shown to influence resistance of young seedlings (Agrawal et al., 1999). 
(a)

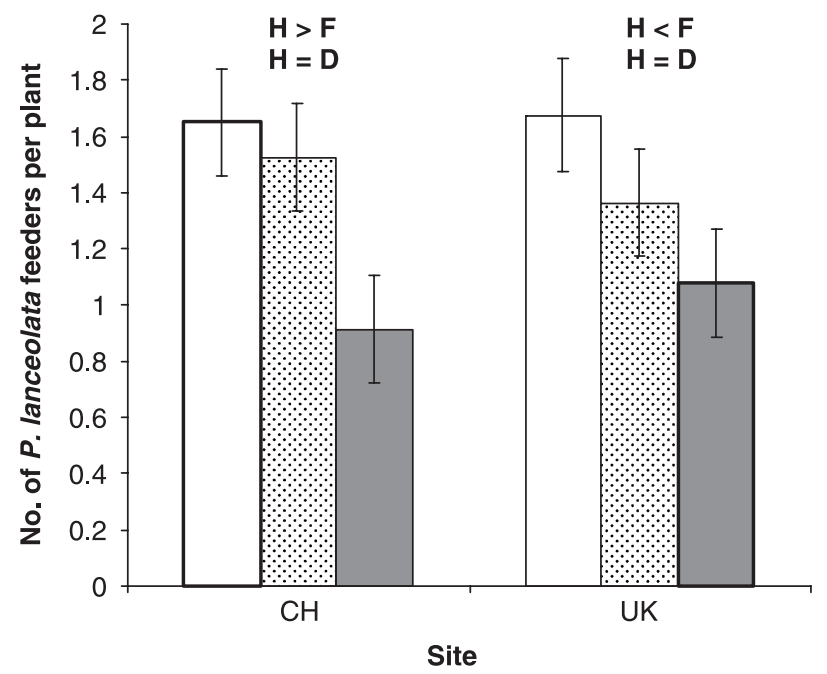

(b)

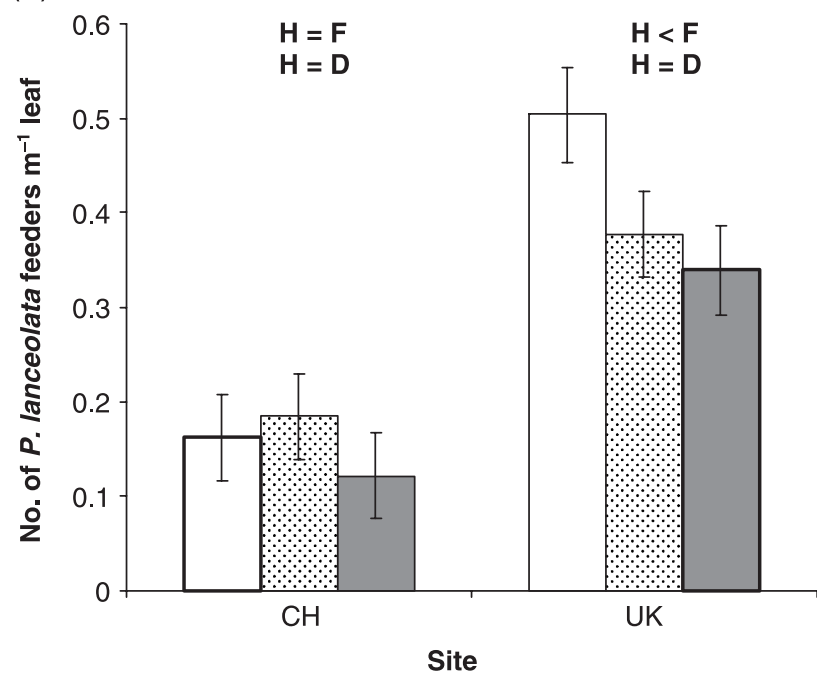

Fig. 3 Number of beetles known to feed on Plantago recovered per plant (a) and per metre of leaf (b) in suction samples taken at the $\mathrm{CH}$ (Switzerland) and UK sites on the CH (white bars), UK (grey bars) and 'local different' (patterned bars) seed provenances. 'Home' seed provenance is shown with a thicker border. $\mathrm{H}$, home; $\mathrm{F}$, foreign; $\mathrm{D}$, 'local different'. Significant home vs foreign contrasts are indicated as $\mathrm{H}<\mathrm{F}$ or $\mathrm{H}>\mathrm{F}$. LSMeans $\pm \mathrm{SE}$.

We measured resistance in 2-yr-old plants, a stage at which potential maternal effects may already have decayed (Agrawal, 2002). Moreover, including juvenile plant size as a covariate in the analysis didn't change the results.

Even if differences among provenances in resistance to local antagonists can be genetically based, environmental factors may still contribute to the phenotypic expression of resistance and tolerance (Mutikainen et al., 2000; Barton \& Bowers, 2006), for example by changing the costs and benefits of producing defence chemicals (Agrawal et al., 2006), or altering the fitness consequences of damage (Kniskern \& Rausher, 2006). If this effect is important, we might expect higher host-plant resistance/tolerance in local provenances than in foreign ones. This would be the case if the local abiotic site conditions are stressful to foreign provenances and thereby negatively affect resistance (plant stress hypothesis; White, 1984). Moreover, faster-growing local plants might be better able to compensate for lost plant tissue through increased growth (Kniskern \& Rausher, 2006).

\section{Local adaptation expressed in resistance to antagonists}

We found highly significant site $\times$ provenance interactions for amount of damage, which is a prerequisite for detecting local adaptation expressed in resistance to antagonists. Additionally, the home vs foreign contrasts were highly significant for both pathogen infection in Holcus and beetle damage in Plantago. Interestingly, the patterns of resistance were opposite for the two species studied.

In Holcus, local provenances had, on average, higher infection rates than foreign provenances, which would indicate plant maladaptation to the local pathogen strain. Such an outcome might be expected if the pathogen evolves faster than its host plant, for example, because of a shorter generation time (Kaltz \& Shykoff, 1998; Greischar \& Koskella, 2007). However, this result is mainly a consequence of the lower infection rates of the UK provenance compared with the $\mathrm{CH}$ and $\mathrm{CZ}$ provenances at the two foreign sites but not at its home site. Although local plants showed, on average, higher infection rates (this study), they nevertheless had higher fitness than foreign plants at their native site (Bischoff et al., 2006). This home-site advantage in fitness was mainly the result of large differences between local and foreign populations in reproductive traits (panicle and seed numbers), while there were no differences in survival and vegetative growth (Bischoff et al., 2006). Thus, rust infection did not contribute to the pattern of plant local adaptation or may even have reduced home-site superiority compared with pathogen-free environments, depending on whether pathogen infection reduced plant fitness. Whether pathogens indeed acted as a selective agent is difficult to answer in this study. Levels of attack were considerable, with $90-100 \%$ of individuals experiencing disease. However, infection occurred late in the season, mostly after plant reproduction, and therefore correlations between amount of infection and reproductive output in the same year are expected to be weak and not very informative (linear fit of seed number on damage: $R^{2}=0.001, P=0.8$ at the $\mathrm{CH}$ site; $R^{2}=0.020, P=0.4$ at the $\mathrm{CZ}$ site; $R^{2}=0.021$, $P=0.3$ at the UK site). It is possible that high infection rates late in the season, when plants accumulate resources for early growth in the spring, will translate into low survival and/or reproduction only in the following year, but we lack the relevant data. The higher fitness of local plants despite higher infection rates might also indicate selection for tolerance rather than resistance in the host plants (Roy \& Kirchner, 2000). 
In Plantago, local provenances were significantly less damaged by the specialist beetles than the foreign provenances, both overall and specifically at the CZ and UK sites. This suggests adaptation of the host plants to the local specialist herbivores. Alternatively, local plants might be better adapted to the physical properties of their home site and thus more able to allocate resources to herbivore-resistance traits. However, no trade-off between growth and chemical defence was found in Plantago (Darrow \& Bowers, 1997, Biere et al., 2004, Barton \& Bowers, 2006). The defence chemicals produced by Plantago, iridoid glycosides, were shown to mediate resistance to herbivory by generalist insect herbivores (Biere et al., 2004). However, higher induction of chemical defence is not likely to increase resistance to specialist herbivore species such as chrysomelid beetles, because they can sequester iridoid glycosides (Willinger $\&$ Dobler, 2001).

In our study, lower beetle damage and higher fitness (Bischoff et al., 2006) of the local Plantago provenances compared with foreign ones indicated that herbivores may have contributed to home-site superiority of the host. The home-site advantage in emergence, survival and reproduction (inflorescence and seed number) resulted in a higher fitness coefficient ( $\lambda$ of Leslie matrices) of the local populations. Parameters of vegetative growth (number of leaves, biomass) did not differ between local and foreign populations (Bischoff et al., 2006). This potential contribution of specialist herbivores to plant local adaptation is further substantiated by the observed negative correlation between beetle damage and reproductive parameters, used as a proxy for fitness (linear fit of inflorescence number on damage, $R^{2}=-0.16, P=00012$ at the $\mathrm{CH}$ site; $R^{2}=-0.07$, $P=0.04$ at the CZ site; $R^{2}=0.05, P=0.08$ at the UK site). However, these results have to be taken with caution, since correlations between amount of damage and reproductive output (fitness) in the same year may be uninformative for predicting patterns of selection on plant defence in a polycarpic perennial. Additional experiments, including an antagonist-free control treatment, would be necessary to establish causality. Sork et al. (1993) also found less damage by leaf herbivores on Northern red oak (Quercus rubra) seedlings transplanted at the maternal site than on seedlings from adjacent subpopulations, indicating local adaptation expressed in resistance. Similarly, populations of Thlaspi caerulescens adapted to metallicolous environments were shown to suffer increased herbivore consumption and decreased fitness in nonmetallicolous sites than in their home environment (Dechamps et al., 2008). Conversely, native and nonnative populations of Chamaecrista fasciculata did not differ in leaf damage, but there was also no effect of herbivores on plant fitness (Abdala-Roberts \& Marquis, 2007).

\section{Competition changed intensity of interaction}

The effect of surrounding vegetation on plant antagonist interaction differed between the two species studied. In Holcus, infection rates by the rust fungus were reduced in the mixed communities compared with the monocultures, which may be explained by reduced transmission of pathogen propagules among plants in the mixture treatment, where nonhost plants act as barriers. In Plantago, beetle damage was higher in plants growing in the competition treatment than in plants growing without competition, while there was no difference between the two competition treatments in the number of beetles per leaf length. This suggests that the similar density of beetles per leaf length across competition treatments resulted in higher attack rates in the relatively smaller Plantago plants of the competition treatment. Barton \& Bowers (2006) found that amounts of defensive iridoid glycosides increased in Plantago in the presence of interspecific neighbours. While their effect on specialist chrysomelid beetles is not known, iridoid glycosides were shown to act as feeding stimulant for an unrelated specialist insect species (Harvey et al., 2005). Alternatively, plants growing in the more competitive environment may have been less able to compensate (in term of new leaf growth) for herbivore damage (Tiffin, 2002), which could also explain why they have a higher amount of damage than plants in monocultures while beetle abundance per leaf area is the same in the two competition treatments.

A remarkable result of our study was that, while interspecific neighbours modified degrees of infestation of plant antagonists, they had little influence on patterns of between-provenance variation (provenance $\times$ environment interactions) in resistance across sites. This suggests that our finding of increased (Plantago) or decreased (Holcus) resistance of local provenances is robust to variation in the surrounding vegetation.

\section{Small-scale differentiation}

For both systems, Plantago-chrysomelid beetles and Holcusrust fungus, we found low population differentiation in host resistance to antagonists at the small geographical scale (between different habitats within countries) compared with the large scale (between countries), except for Holcus resistance to rust at the $\mathrm{CH}$ site, where the home provenance was more damaged than the 'local different' one. Dispersal of antagonists might have limited small-scale differentiation of the antagonists and thus small-scale differences in resistance/tolerance patterns of the host populations. Thrall et al. $(2001,2002)$ also found stronger differentiation in host resistance at the large spatial scale than at the small scale, in a plant-pathogen system where the rate of dispersal of the pathogen was higher than that of the host. Overall, pathogen populations had a greater ability to infect host plants from their own region than from foreign regions (Thrall et al., 2002), similar to what we found for the Holcus-rust pathosystem.

The low small-scale differentiation in host resistance to antagonists is in contrast to differentiation in other plant traits which was found to be large at small scales (Bischoff et al., 2006). 'Local different' populations had lower fitness than the home populations, even though they were similarly affected 
by plant antagonists. Genetic assemblages of plant antagonists might be similar at small scales, owing to their higher dispersal rate, and other factors (i.e. abiotic conditions) might be more important in determining fitness differences between two populations from the same region.

\section{Conclusion}

The large-scale translocation of plants during the restoration of diverse ecosystems has raised questions about the risks associated with the introduction of maladapted genotypes that may hybridize with locally adapted conspecifics (Hufford \& Mazer, 2003). Here we show that populations of two widespread plant species used in ecological restoration are highly differentiated in the degree of resistance to specialist antagonists, suggesting that plant translocations will also alter interactions with organisms of higher trophic levels. However, the two plant species showed contrasting patterns of population differentiation in resistance to local antagonists, indicating that it will be difficult to predict the exact outcome of translocations on plant-antagonist interactions without detailed case-by-case studies.

\section{Acknowledgements}

We thank all students and technicians who helped in the field, particularly Franziska Leuenberger, Lus Escher, Blanka Divisova, Jemma Daniels, Katherine Robinson and Victoria Chapman. We further thank all other members of the 'Tlinks' team for their contribution to the project. This project was supported by the Swiss Federal Office for Education and Science (project 01.0086 to H. Müller-Schärer) within the Framework V Program of the European Community EVK2-CT-2001-00123 'Tlinks' (Trophic linkages between above- and below-ground organisms as a key to successful restoration of biodiversity on ex-arable land across Europe).

\section{References}

Abdala-Roberts L, Marquis RJ. 2007. Test of local adaptation to biotic interactions and soil abiotic conditions in the ant-tended Chamaecrista fasciculate (Fabaceae). Oecologia 154: 315-326.

Agrawal AA. 2002. Herbivory and maternal effects: mechanisms and consequences of transgenerational induced plant resistance. Ecology 83: 3408-3415.

Agrawal AA, Laforsch C, Tollrian R. 1999. Transgenerational induction of defences in animal and plants. Nature 401: 60-63.

Agrawal AA, Lau JA, Hamback PA 2006. Community heterogeneity and the evolution of interactions between plants and insect herbivores. Quarterly Review of Biology 81: 349-376.

Barton KE, Bowers MD. 2006. Neighbour species differentially alter resistance phenotypes in Plantago. Oecologia 150: 442-452.

Beddows AR. 1961. Biological flora of the British Isles, Holcus lanatus L. Journal of Ecology 49: 421-430.

Biere A, Marak HB, van Damme JMM. 2004. Plant chemical defense against herbivore and pathogens: generalized defense or trade-offs. Oecologia 140: 430-441
Bischoff A, Crémieux L, Smilauerova M, Lawson CS, Mortimer SR, Dolezal J, Lanta V, Edwards AR, Brook AJ, Macel M et al. 2006. Detecting local adaptation in widespread grassland species - the importance of scale and local plant community. Journal of Ecology 94: $1130-1142$.

Blossey B, Nötzold R. 1995. Evolution of increased competitive ability in invasive nonindigenous plants: a hypothesis. Journal of Ecology 83: 887-889.

Bos M, Harmens H, Vrieling K. 1986. Gene flow in Plantago. I. Gene flow and neighborhood size in P. lanceolata. Heredity 56: 43-54.

Bullok JA. 1992. Host plants of British beetles: a list of recorded associations. Essex, UK: Cravitz Publishing Company Ltd.

Carson WP, Root RB. 2000. Herbivory and plant species coexistence: community regulations by an outbreaking phytophagous insect. Ecological Monographs 70: 73-99.

Cavers PB, Bassett IJ, Crompton CW. 1980. The biology of Canadian weeds 47. Plantago lanceolata L. Canadian Journal of Plant Science 60: $1269-1282$.

Darrow K, Bowers MD. 1997. Phenological and population variation in iridoid glycosides of Plantago lanceolata (Plantaginaceae). Biochemical Systematics and Ecology 25: 1-11.

Dechamps C, Noret N, Mozek R, Escarré J, Lefebvre C, Gruber W, Meerts P. 2008. Cost of adaptation to a metalliferous environment for Thlaspi caerulescens: a field reciprocal transplantation approach. New Phytologist 177: 167-177.

Douget S. 1994. Coléoptères chrysomelidae, Vol. 2. Alticinae. Fauna de France 80. Paris, France: Fédération Française des Sociétés de Sciences Naturelles.

Galloway LF, Fenster CB. 2000. Population differentiation in an annual legume: local adaptation. Evolution 54: 1173-1181.

Gardner DE, Hodges CS Jr. 1989. The rust fungi (Uredinales) of Hawaii. Pacific Science 43: 41-55.

Greischar MA, Koskella B. 2007. A synthesis of experimental work on parasite local adaptation. Ecology Letters 10: 418-434.

Harvey JA, Van Nouhuys S, Biere A. 2005. Effects of quantitative variation in allelochemicals in Plantago lanceolata on development of a generalist and specialist herbivore and their endoparasitoids. Journal of Chemical Ecology 31: 287-301.

Hufford KM, Mazer SJ. 2003. Plant ecotypes: genetic differentiation in the age of ecological restoration. Trends in Ecology and Evolution 18: $147-155$.

Jarosz AM, Davelos AL. 1995. Effects of disease in wild plant-populations and the evolution of pathogen aggressiveness. New Phytologist 129: 371-387.

Joshi J, Schmid B, Caldeira MC, Dimitrakopoulos PG, Good J, Harris R, Hector A, Huss-Danell K, Jumpponen A, Minns A et al. 2001. Local adaptation enhances performance of common plant species. Ecology Letters 4: 536-544.

Kaltz O, Shykoff JA. 1998. Local adaptation in host-parasite systems. Heredity 81: 361-370.

Kawecki TJ, Ebert D. 2004. Conceptual issues in local adaptation. Ecology letters 7: 1225-1241.

Keane RM, Crawley MJ. 2002. Exotic plant invasions and the enemy release hypothesis. Trends in Ecology and Evolution 17: 164-170.

Kittelson PM. 2004. Sources of variation in insect density on Lupinus arboreus Sims: effects of environment, source population and plant genotype. American Midland Naturalist 152: 323-335.

Kniskern JM, Rausher MD. 2006. Environmental variation mediates the deleterious effects of Coleosporium ipomoeae on Ipomoea purpurea. Ecology 87: 675-685.

Lau JA. 2006. Evolutionary responses of native plants to novel community members. Evolution 60: 56-63.

Levine JM, Vilà M, D’Antonio CM, Dukes JS, Grigulis K, Lavorel S. 2003. Mechanisms underlying the impacts of exotic plant invasions. Proceedings of the Royal Society of London B 270: 775-781.

Linhart YB, Grant MC. 1996. Evolutionary significance of local genetic 
differentiation in plants. Annual Review of Ecology and Systematics 27: 237-277.

Macel M, Lawson CS, Mortimer SR, Šmilauerova M, Bischoff A, Crémieux L, Doležal J, Edwards AR, Lanta V, Bezemer TM et al. 2007. Climate vs. soil factors in local adaptation of two common plant species. Ecology 88: 424-433.

Marquis RJ. 1992. The selective impact of herbivores. In: Fritz RS, Simms EL, eds. Plant resistance to herbivores and pathogens: ecology, evolution and genetics. Chicago, IL, USA: University of Chicago Press, 301-325.

Montalvo AM, Ellstrand NC. 2000. Transplantation in the subshrub Lotus scoparius: I. Test of the home site advantage hypothesis. Conservation Biology 14: 1034-1045.

Mutikainen P, Salonen V, Puustinen S, Koskela T. 2000. Local adaptation, resistance, and virulence in a hemiparasitic plant-host plant interaction. Evolution 54: 433-440.

Nuismer SL. 2006. Parasite local adaptation in a geographic mosaic. Evolution 60: 24-30.

Ross MD. 1973. Inheritance of self-incompatibility in Plantago lanceolata. Heredity 30: 169-176.

Rossi AM, Stiling P. 1998. The interactions of plant clone and abiotic factors on a gall-making midge. Oecologia 116: 170-176.

Roy BA, Kirchner JW. 2000. Evolutionary dynamics of pathogen resistance and tolerance. Evolution 54: 51-63.

Saltonstall K. 2002. Cryptic invasion by a nonnative genotype of the common reed, Phragmites australis, into North America. Proceedings of the National Academy of Sciences, USA 99: 2445-2449.

Sork VL, Stowe KA, Hochwender C. 1993. Evidence for local adaptation in closely adjacent subpopulations of Northern red oak (Quercus rubra L.) expressed as resistance to leaf herbivores. American Naturalist 142: 928-936.

Stiling P, Bowdish TI. 2000. Direct and indirect effects of plant clone and local environment on herbivore abundance. Ecology 81: 281-285.

Thompson JD, Turkington R. 1988. Holcus lanatus L., The biology of Canadian weeds, No. 82. Canadian Journal of Plant Science 68: 131-147.

Thompson JN. 1999. Specific hypotheses on the geographic mosaic of coevolution. American Naturalist 153: S1-S14.

Thrall PH, Burdon JJ, Bever JD. 2002. Local adaptation in the Linum marginale - Melamspora lini host-pathogen interaction. Evolution 56: $1340-1351$.

Thrall PH, Burdon JJ, Young AG. 2001. Variation in resistance and virulence among demes of a single host-pathogen metapopulation. Journal of Ecology 89: 736-748.

Tiffin P. 2002. Competition and time of damage affect the pattern of selection acting on plant defense against herbivores. Ecology 83: 1981-1990.

Tonsor SJ. 1985. Intrapopulational variation in pollen-mediated gene flow in Plantago lanceolata L. Evolution 39: 775-782.

White TCR. 1984. The abundance of invertebrate herbivores in relation to the availability of nitrogen in stressed food plants. Oecologia 63: 90-105.

Willinger G, Dobler S. 2001. Selective sequestration of iridoid glycosides from their host plants in Longitarsus flea beetles. Biochemical Systematics and Ecology 29: 335-346.

Zadoks JC, Schein RD. 1979. Epidemiology and plant disease management. New York, NY, USA: Oxford University. 